\title{
BMJ Open Product attributes important to US adult consumers' use of electronic nicotine delivery systems: a discrete choice experiment
}

\author{
Christine E Kistler, ${ }^{1,2}$ Leah M Ranney, ${ }^{1}$ Erin L Sutfin, ${ }^{3}$ Keith Chrzan, ${ }^{4}$ \\ Christopher J Wretman, ${ }^{5}$ Chineme Enyioha, ${ }^{1}$ Clare Meernik, ${ }^{6}$ Micah Berman, ${ }^{7}$ \\ Gary A Zarkin, ${ }^{8}$ Adam O Goldstein ${ }^{1,2}$
}

To cite: Kistler CE, Ranney LM, Sutfin EL, et al. Product attributes important to US adult consumers' use of electronic nicotine delivery systems: a discrete choice experiment. BMJ Open 2019;9:e027247. doi:10.1136/ bmjopen-2018-027247

- Prepublication history and additional material for this paper are available online. To view these files, please visit the journal online (http://dx.doi. org/10.1136/bmjopen-2018027247).

Received 13 November 2018 Revised 13 June 2019 Accepted 3 July 2019

Check for updates

(C) Author(s) (or their employer(s)) 2019. Re-use permitted under CC BY-NC. No commercial re-use. See rights and permissions. Published by BMJ.

For numbered affiliations see end of article.

Correspondence to

Dr Christine E Kistler;

christine_kistler@med.unc.edu

\section{ABSTRACT}

Objective To understand the importance of electronic nicotine delivery systems (ENDS) product attributes to adult consumers in the USA by age and gender.

Design Cross-sectional survey with a discrete choice experiment (best-worst, case 2, scaling) of 19 choice tasks in which participants answered what would make them most want to use and least want to use an ENDS product.

Setting and participants A national sample of adults (aged 18+ years) in the USA who had tried an ENDS product at least once.

Measures We included 9 ENDS attributes with levels that varied across 19 choice tasks. We performed a multinomial logistic regression to obtain overall importance scores, attribute-level part-worth utilities and most important attribute.

Results of 660 participants, $81 \%$ were white, $51 \%$ women and $37 \%$ had at least a 4 -year college degree with an average age of 42.0 years (SD \pm 19.4 ). The attributes had the following importance: harms of use $17.6 \%$; general effects $14.1 \%$; cessation aid $12.6 \%$; purchase price $12.1 \%$; monthly cost $12.0 \%$; nicotine content $11.4 \%$; flavour availability $8.4 \%$; device design $7.2 \%$; modifiability $4.6 \%$. Harms of use was the most important attribute for all ages and genders $(p<0.05)$; variation in other important attributes existed by age though not by gender.

Conclusion This study identified the importance of nine ENDS attributes. Perceived harms of use of ENDS use appeared most important, and modifiability was least important. Variation by consumer group existed, which may allow for targeted interventions to modify ENDS use.

\section{INTRODUCTION}

Although its health effects remain unclear, the use of electronic nicotine delivery systems (ENDS) in the USA continues to grow even in the face of impending regulation. ${ }^{1}$ While the use of combustible tobacco cigarettes has declined, the US ENDS market now exceeds $\$ 8$ billion. ${ }^{2}{ }^{3}$ The rise in the use of ENDS has occurred despite mixed evidence about its harm reduction effects or use as a
Strengths and limitations of this study:

- Large US sample using a robust experimental design, a best-worst scaling, case 2 method, incorporating large numbers of relevant attributes of electronic nicotine delivery systems (ENDS).

> Consumers found different attributes of ENDS products important to their use.

- Perceived harms of ENDS use appeared most important to their choice of ENDS products, and modifiability was least important.

- Variation by consumer group existed, which may allow for targeted interventions to modify ENDS use.

- Limitations include the convenience sample of US ENDS users, and the use of an experimental design which may invite more socially acceptable responses as opposed to direct purchasing observations.

tobacco cessation aid. ${ }^{4}$ Given the uncertainty around ENDS, initial regulations were piecemeal and varied from state to state. However, in 2016, the Food and Drug Administration (FDA) issued a regulation deeming ENDS to fall under its authority. ${ }^{5}$ These regulations will impose a variety of restrictions on ENDS manufacturing, sales and marketing. Notably, however, the FDA has postponed implementation of some of the rules requirements, citing the possibility that ENDS have the 'potential to make a notable public health difference'. ${ }^{6}$ As the potential benefits and harms of ENDS become clear, regulators and public health groups will need to understand how their proposed regulations will likely affect consumers' use. Consumers use ENDS due to a variety of product attributes that may be amenable to regulation or public health campaigns. ${ }^{7}$ Regulators and public health groups need to know the incremental role of individual product attributes on the decision to use ENDS products so that they can make 
evidence-based policies depending on how they want to modify ENDS use.

A widely used method in behavioural economics to understand consumer use is discrete choice experiments (DCE) ${ }^{8}{ }^{9}$ Once the relationship between consumers' use and product attributes is understood, regulators can consider whether and how to address the most important attributes to most of the consumers to either increase or decrease product use. While DCEs have been conducted to examine consumers' attitudes towards combustible tobacco regulations and smoking cessation, ${ }^{10-14}$ only one has examined potential ENDS use. ${ }^{15}$ This recently published study conducted in Canada examined only four ENDS attributes: flavour, nicotine content, health warnings and price ${ }^{15}$; finding that health risks and efficacy as a tobacco cessation aid were the two most important attributes to consumers. However, this study only examined four attributes and included non-smokers and non-ENDS users.

Knowledge from our formative qualitative work was used to create a DCE with a larger number of attributes focused on ENDS users. We examined the list of a dozen attributes that are important to consumers, which we developed from a recent structured content analysis. ${ }^{16}$ Among these 12 attributes, we found 9 attributes that appeared related to the ENDS device itself. ${ }^{16}$ We chose to look at the device-related attributes because these attributes may be more easily regulated than other psychosocial attributes such as the ability to vape in public or as a social outlet. ${ }^{17}$ We designed and fielded a DCE study using a best-worst scaling experiment among the national US sample of ENDS users.

\section{METHODS}

\section{Study design}

We conducted a one-time survey including a best-worst scaling, case 2 design DCE of the importance of ENDS product attributes. The final version of the survey was fielded using the Research Now survey panel between 26 August and 31 August 2016. Participants were remunerated from Research Now in accordance with their usual rate.

\section{Patient and public involvement}

The attributes used in the DCE were developed through focus groups conducted as part of prior research. ${ }^{19}$ The study involved participants in a pretest phase using an academic mass email system. Twelve individuals pretested the survey between 9 May and 14 May 2016. Incentive for completing the survey included possibly receiving one of four gift cards valued at $\$ 50$ each. Feedback from the pretest led to both condensing and simplifying the language of the survey. Clarity of the survey was again improved after another round of testing with 75 survey panellists recruited from Research Now, a research survey company, between 15 August and 16 August 2016. The second episode of testing also led to language alterations surrounding questions on the flavour attribute and its levels to ensure comprehension. Participants were not involved in the recruitment to or conduct of the study. Participants in the final version of the survey did not receive their study results.

\section{Participants}

We recruited 660 members of the Research Now survey panel aged 18 years and older who reported having used ENDS at least once in their lifetime to complete the ENDS survey. Research Now is one of the major online survey panel companies with over 140 million finished surveys annually. Participants had to live in the USA and be able to complete an electronic survey in English. We specifically oversampled for older adults and minimum quotas to ensure near equal balance of gender.

\section{Survey design}

The survey was designed to include a best-worst scaling experiment related to ENDS use followed by a series of tobacco and ENDS-related questions. The survey included 19 best-worst scaling choice tasks, followed by questions on each participant's demographics, personality, current and past use of ENDS and tobacco products and prior attempts to quit tobacco use. Sawtooth Software was used to design the survey. Prior to the best-worst tasks, the survey provided an explanation for each of the attributes, as well as an example task involving car attribute preference followed by an example of a best-worst scaling task (figure 1). The participants were told that some of the attributes were real but others were not and were asked, for the purposes of the study, to pretend they were all real and imagine each choice task as a new device. As opposed to other types of DCE methods where consumers choose between ENDS products, for each of the 19 choice tasks, participants selected one of five listed attribute levels that they felt most likely to encourage and least likely to encourage their use of a theoretical ENDS product. While other approaches such as a classical DCE would also yield importance scores, past studies demonstrated user fatigue and attribute dominance due to complex

Please imagine this is a new e-cigarette that has just become available for purchase. When you look at the 5 features of the e-cigarette, which feature makes you most want to use the ecigarette and which feature makes you least want to use the e-cigarette.

(1 of 19)

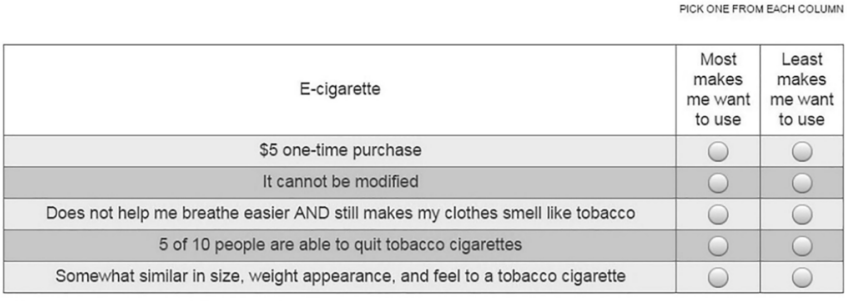

Click the forward arrow button to continue...

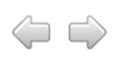

Figure 1 Example of a best-worst scaling, case 2 task. 
and overwhelming survey questions, whereas best-worst scaling, though not case 2, has been used in other areas of tobacco control. ${ }^{20-23}$ Additionally, best-worst scaling case 2 methodology was preferred because it leads to scores on a common scale, permitting direct comparison between all attribute levels within the study, but not just direct comparisons among levels within the same attribute (as is the case for other DCE methods). ${ }^{24}{ }^{25}$ The 660 participants received 1 of 50 versions of the survey using a partial profile design. We sought efficiency by using a computer search algorithm to generate a design that showed each of a given attribute's levels an equal number of times (one-way level balance) and each pairing of a given attribute level with the levels of other attributes an equal number of times (two-way level balance that reduces correlations among the attributes). These two criteria will maximise both level balance and orthogonality, the two constituents of design efficiency for experimental design for a set of single profiles. Overall, each attribute level was seen about three times per participant (2.97), and each valid cross-attribute pair was seen not quite half the time by each participant ( 0.42 times). Reliable best-worst utilities can be obtained as long as each participant sees each level about three times. ${ }^{26}$ The order of attributes varied across the survey blocks so that positional balance was maintained.

\section{Best-worst scaling attributes and levels}

The nine attributes were included with a definition in the survey. Their definitions can be found in online appendix table 1. For the rest of the paper, we will refer to these nine as harms of use, general effects, cessation aid, purchase price, monthly cost, nicotine content, flavour availability, device design and modifiiability. ${ }^{16}$ We chose to divide cost into a separate purchase price and monthly cost attributes because of the variation that can be seen in each; the focus group members mentioned the two attributes separately as well. Rates of tobacco cessation for ENDS products were drawn from the evidence that ENDS are often used as a tobacco cessation aid regardless of actual effectiveness. It is worth noting that medications prescribed for assisting in tobacco cessation (eg, bupropion, varenicline, nicotine containing products) have 2 out of 10 success rate at best. ${ }^{27}$ Nicotine content levels were drawn from the current spectrum of labelled nicotine concentrations. ${ }^{28}$ In addition to the actual concentration, we included a label of 'none', 'low', etc., to denote where a particular concentration falls in the range of concentrations.

\section{Other measures}

Participants responded to questions about sex, age, race and ethnicity, perceptions of general health, ${ }^{29}$ education level and yearly household income. The survey then collected details about each participants' tobacco and ENDS use behaviours. Items included the heaviness of smoking index that asks participants 'At present, how long after waking do you wait before having your first cigarette (in mins)?' and 'How many cigarettes do you smoke per day at present? ${ }^{30}$ and other questions from the National Adult Tobacco Survey Questionnaire, 2012-2013, such as age of first cigarette, number of cigarettes smokes per day and smoking days per month. ${ }^{31}$

\section{Analysis}

In DCEs, respondents are given tasks that combine possible varieties of product attributes and asked to make a choice, in our case, which attribute of the product was important to their use. With enough choice tasks, estimated importance scores can be generated, indicating which attribute most influenced their choices. The statistical model underlying best-worst scaling assumes that the relative choice probability of a given pair of bestworst choices is proportional to the distance between the two attribute levels on the latent utility scale. The pair of attribute levels chosen maximises the difference in the part-worth utilities for a given choice task. These distances between attribute levels are modelled as a difference model, with variations on best-worst scaling sometimes called 'maximum difference scaling. ${ }^{32}$ Using a multinomial regression model, these differences can provide the part-worth utilities relative to a single attribute level rather than relative to the sample mean. ${ }^{24}$ Part-worth utilities are zero-centred numerical values that represent the relative desirability of the levels within each attribute. The higher the number, the more desirable the attribute's level is to participants. Importance scores were then calculated based on the difference between minimum and maximum part-worth utilities within an attribute. ${ }^{25}{ }^{33}$ The total importance of all attributes to a decision is $100 \%$, with each attribute given a percentage of that total importance. Most important attribute was determined by comparing the importance scores for each individual, defining the attribute with the largest importance score as most important. In order to examine changes in attribute importance by age and gender, we performed a dependent $z$-test of proportions to compare the most important attribute with the next highest ranked attribute by age and gender.

\section{RESULTS}

Of 900 individuals surveyed, 660 participants had used ENDS at least one time. Participants had a mean age of 42 years $(\mathrm{SD} \pm 19.4)$ with a range from 18 to 82 years and were evenly split women versus men (51\% vs $49 \%)$ (table 1). Most participants were white $(81 \%)$, making less than $\$ 60000$ annually $(60 \%)$ and self-reported very good or excellent health $(60 \%)$. Sixty-four percent had used ENDS in the last 30 days. Almost all participants $(92 \%)$ reported a history of traditional tobacco products and most $(85 \%)$ had tried to quit tobacco in the past 12 months. Pearson's $\chi^{2}$ tests of the relation between age and tobacco use characteristics found statistically significant $(\mathrm{p}<0.05)$ differences between subgroups of young (18-24 years), middle-aged (25-49 years) and older (50+ years) adults. For example, young adult participants 
Table 1 Participants' characteristics, n (\%)

\begin{tabular}{|c|c|c|c|c|}
\hline Characteristics & Total, $\mathrm{n}=660$ & $\begin{array}{l}\text { Age 18-24 years, } \\
n=169\end{array}$ & $\begin{array}{l}\text { Age } 25-49 \text { years, } \\
\mathrm{n}=242\end{array}$ & $\begin{array}{l}\text { Age } 50+\text { years, } \\
\mathrm{n}=249\end{array}$ \\
\hline Age, mean (SD) & $42.0(19.4)$ & $22.2(1.6)$ & $32.1(7.7)$ & $65.0(6.9)$ \\
\hline Female & 334 (51\%) & $90(53 \%)$ & $120(49 \%)$ & $124(50 \%)$ \\
\hline \multicolumn{5}{|l|}{ Race } \\
\hline White & 532 (81\%) & 113 (67\%) & 191 (79\%) & 228 (92\%) \\
\hline Black & $42(6 \%)$ & $14(8 \%)$ & $18(7 \%)$ & $10(4 \%)$ \\
\hline Asian-American & $40(6 \%)$ & $20(12 \%)$ & $18(7 \%)$ & $2(1 \%)$ \\
\hline Other & $46(7 \%)$ & $22(13 \%)$ & $15(6 \%)$ & $9(4 \%)$ \\
\hline Hispanic or Latino/Latina & 94 (14\%) & $42(25 \%)$ & $45(19 \%)$ & $7(3 \%)$ \\
\hline College degree or higher & 247 (37\%) & $37(22 \%)$ & $113(47 \%)$ & 97 (38\%) \\
\hline Overall health, very good or excellent & $396(60 \%)$ & $110(65 \%)$ & $160(66 \%)$ & $126(51 \%)$ \\
\hline \multicolumn{5}{|l|}{ Annual household income } \\
\hline$\$ 0$ to $\$ 29999$ & 149 (23\%) & $52(31 \%)$ & $51(21 \%)$ & $46(18 \%)$ \\
\hline$\$ 30000$ to $\$ 59999$ & $247(37 \%)$ & $75(44 \%)$ & $85(35 \%)$ & $87(35 \%)$ \\
\hline$\$ 60000$ to $\$ 89999$ & 156 (24\%) & $25(15 \%)$ & $73(30 \%)$ & $58(23 \%)$ \\
\hline$\$ 90000$ or more & $106(16 \%)$ & $17(10 \%)$ & $33(14 \%)$ & $58(23 \%)$ \\
\hline $\begin{array}{l}\text { Knowledge that quitting smoking with help is } \\
\text { more successful than without }\end{array}$ & 310 (47\%) & $75(44 \%)$ & $108(45 \%)$ & $127(51 \%)$ \\
\hline Used ENDS in last 30 days $†$ & 387 (64\%) & $109(71 \%)$ & $153(69 \%)^{*}$ & $125(54 \%)^{*}$ \\
\hline $\begin{array}{l}\text { Used flavoured ENDS in last } 30 \text { days, of current } \\
\text { ENDS usersł }\end{array}$ & $296(70 \%)$ & $93(79 \%)^{\star}$ & $134(79 \%)^{\star}$ & $69(52 \%)^{*}$ \\
\hline Anticipates ENDS use in next year & $478(72 \%)$ & $121(72 \%)$ & $193(80 \%)^{\star}$ & $164(66 \%)^{*}$ \\
\hline Ever used traditional tobacco products & 607 (92\%) & $154(91 \%)$ & $221(91 \%)$ & $232(93 \%)$ \\
\hline Age at first cigarette, mean (SD) $\dagger$ & $17(6)$ & $16(3)$ & $18(5)$ & $18(8)$ \\
\hline Smokes more than one pack/day§ & $54(12 \%)$ & $3(3 \%)^{*}$ & $12(8 \%)^{*}$ & $39(23 \%)^{\star}$ \\
\hline First smoke within $30 \mathrm{~min}$ of waking $\neq \S$ & $256(59 \%)$ & $48(44 \%)^{*}$ & $89(59 \%)$ & $119(70 \%)^{*}$ \\
\hline Tobacco quit attempt in past 12 months§ & 369 (85\%) & $87(79 \%)^{\star}$ & $130(85 \%)$ & $152(89 \%)$ \\
\hline
\end{tabular}

${ }^{*} \mathrm{P}<0.05$; test versus total.

$\dagger \mathrm{t}=607,154,221$ and 232, respectively. $\neq \mathrm{n}=420,117,170$ and 133 , respectively. $\S \mathrm{n}=432,110,152$ and 170 , respectively. ENDS, electronic nicotine delivery systems.

were more likely to have used ENDS in the last 30 days $(p=0.036)$ and to have used flavoured ENDS $(p=0.012)$. Older adults were less likely to have used ENDS in the past 30 days $(p<0.001)$ and more likely to smoke one pack/day of traditional tobacco $(\mathrm{p}<0.001)$ (see table 2$)$.

\section{Importance of ENDS attributes overall and by subgroup}

The overall importance scores for the nine attributes are found in figure 2. The attributes had the following importance distribution: harms of use $17.6 \%$; general effects $14.1 \%$; cessation aid $12.6 \%$; purchase price $12.1 \%$; monthly cost $12.0 \%$; nicotine content $11.4 \%$; flavour availability $8.4 \%$; device design $7.2 \%$ and modifiability $4.6 \%$. Independent t-tests of the importance scores by gender found that when compared with men, women participants were more likely to give importance to harms of uses $(\Delta+9.7 \% ; \mathrm{p}<0.001)$ and general effects $(\Delta+8.1 \%$; $\mathrm{p}=0.002)$ and less likely to give importance to purchase price $(\Delta-8.3 \% ; \mathrm{p}=0.011)$ and monthly cost $(\Delta-6.8 \%$; $\mathrm{p}=0.008)$.

Numerous statistically significant differences were found by age subgroups. Younger adults compared with middle-aged and older adults together were more likely to give importance to modifiability $(\Delta+22 \%$; $\mathrm{p}=0.004)$ and less likely to give importance to purchase price $(\Delta-11 \% ; \mathrm{p}=0.006)$. Middle-aged adults compared with young and older adults together were more likely to give importance to modifiability $(\Delta+24 \% ; \mathrm{p}=0.001)$ and less likely to give importance to harms of use $(\Delta-5 \%$; $\mathrm{p}=0.027$ ). Older adults compared with middle-aged and young adults together were more likely to give importance to purchase price $(\Delta+11 \% ; \mathrm{p}=0.004)$ and less likely to give importance to modifiability $(\Delta-34 \% ; \mathrm{p}<0.001)$. 
Table 2 Final ENDS attributes, levels and mean utilities, $n=660$

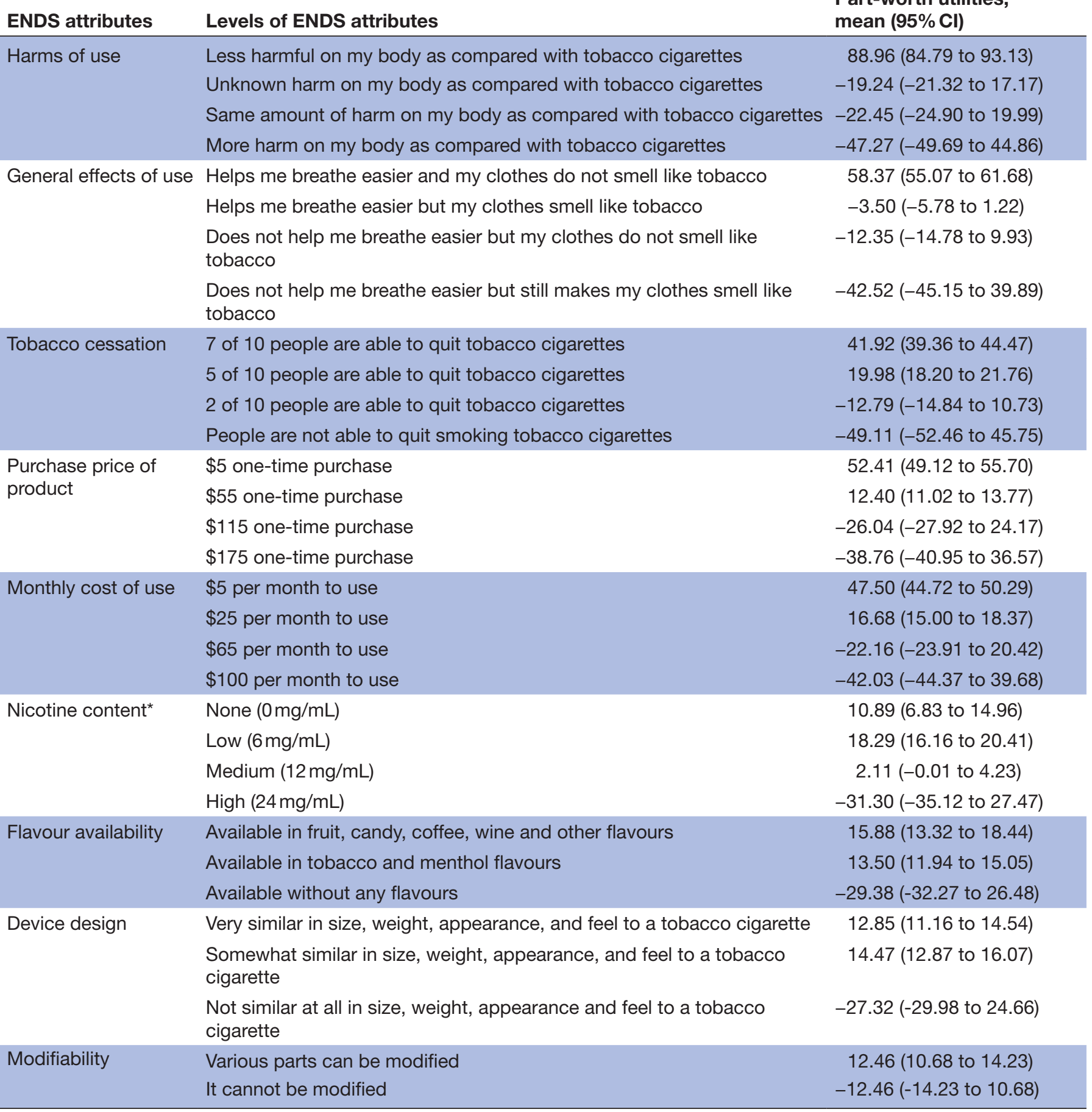

*Nicotine levels corresponded to what the current literature designated as low, medium and high levels of nicotine.

ENDS, electronic nicotine delivery systems.

\section{Part-worth utilities of ENDS attribute levels}

The part-worth utility scores for the levels of the nine attributes are shown in table 2. Harms of use had the level with the highest part-worth utility of 88.96 (90\% CI: 84.79, 93.13), followed by general effects with a level at 58.37 (90\% CI: $55.07,61.68)$ and purchase price at 52.41 (90\% CI: $49.12,55.70)$. Cessation aid had the level with the lowest part-worth utility of -49.11 (90\% CI: $-52.46,-45.75)$, followed by harms of use at -47.27 (90\% CI: $-49.69,-44.86)$.

\section{Most important ENDS attribute overall and by subgroup}

After examining the importance scores for each individual, harms of uses was the most important attribute for $49 \%$ of participants (table 3). Nicotine content was next 


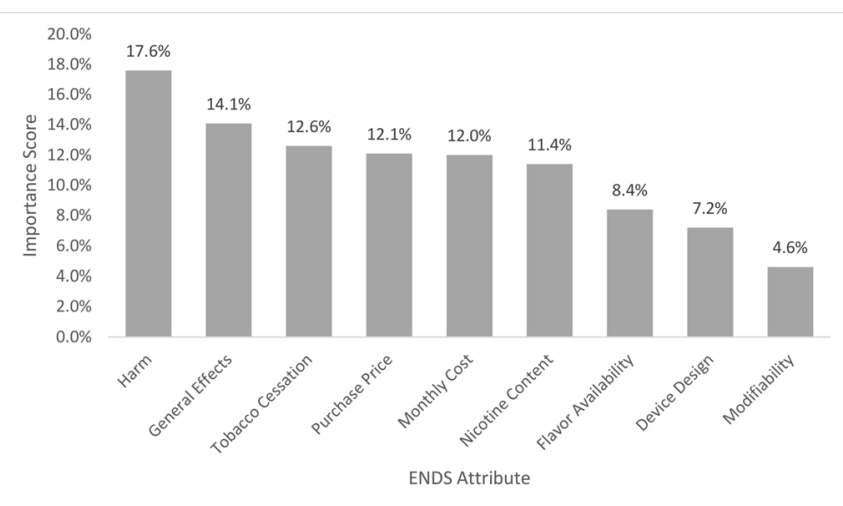

Figure 2 Importance of ENDS characteristics, $\mathrm{n}=660$. ENDS, electronic nicotine delivery systems.

most frequent (13\%) and purchase price was third (12\%). A goodness-of-fit $\chi^{2}$ test determined that the nine attributes differed from expected and thus were not equally distributed among participants $(p<0.001)$. Also, dependent $z$-tests of the proportions of the second through ninth ranked attributes against harms of use found that all were significantly lower ranked and were less likely to be chosen as most important (range: $\Delta-83 \%-99 \%$; $\mathrm{p}<0.001$ ). Aside from nicotine content compared with harms of use, stepped tests of each attribute against its nearest found that only device design $(\mathrm{p}=0.005)$ and modifiability $(p=0.020)$ were statistically significantly less important.

The nine attributes also statistically significantly differed from the expected distribution by the subgroups for age and gender $(p<0.001)$. Pearson's $X^{2}$ tests of the relation between the age subgroups and most important attribute found that general effects was the most important attribute for younger adults as compared with other ages $(\mathrm{p}<0.001)$. Compared with younger and older adults, general effects was less likely to be the most important attribute for middle-aged adults $(\mathrm{p}=0.029)$ and flavour availability was more likely to be most important $(\mathrm{p}=0.018)$. Compared with both younger and middle-aged adults, harms of use was more likely to be important $(\mathrm{p}=0.016)$ and flavour availability was less likely to be important $(\mathrm{p}=0.003)$. There were no statistically significant differences in the distribution of most important attributes by gender although harms of use $(\mathrm{p}=0.061)$ and cessation aid $(\mathrm{p}=0.075)$ approached significance.

\section{DISCUSSION}

In our study of US adult ENDS consumers, we found that harms of use had the highest importance to consumers' choice of an ENDS product. Other than cost (ie, purchase price and monthly cost), the attributes with the highest importance scores hinged on consumers' perceptions of efficacy as a harm reduction strategy (harms of use), health benefit (general effects) and tobacco cessation (cessation aid), respectively. Consumers of different ages varied in importance they placed on different ENDS product characteristics. As more evidence about these products' ability to benefit or harm consumers is more fully understood, public health initiatives could target these perceptions. Variation by consumer group existed, which may allow for targeted interventions to reduce or enhance ENDS use in any given consumer group.

ENDS products are marketed as healthier than combustible tobacco products, ${ }^{34}$ but the evidence regarding the impact of ENDS products on human health is slowly emerging. National Academies of Science, Engineering, and Medicine recently released a report on the public health consequences of ENDS products. ${ }^{35}$ While there is substantial evidence that, except for nicotine, exposure to potentially toxic substances from ENDS is significantly lower compared with combustible tobacco products, there is also substantial evidence that exposure to ENDS aerosols can induce lung dysfunction and oxidative stress in human tissue. ${ }^{36}$ The long-term effects on cardiovascular outcomes, cancer or other health conditions are unclear. Our work should add a sense of urgency to the push for ongoing research into the evidence for and against ENDS products as a harm reduction strategy. The idea that an

\begin{tabular}{|c|c|c|c|c|c|c|}
\hline ENDS characteristics & $\begin{array}{l}\text { Total } \\
\mathrm{n}=660\end{array}$ & $\begin{array}{l}\text { Age } 18- \\
24 \text { years } n=169\end{array}$ & $\begin{array}{l}\text { Age } 25- \\
49 \text { years } n=242\end{array}$ & $\begin{array}{l}\text { Age } 50+\text { years } \\
\mathrm{n}=249\end{array}$ & $\begin{array}{l}\text { Male } \\
n=326\end{array}$ & $\begin{array}{l}\text { Female } \\
\mathrm{n}=334\end{array}$ \\
\hline Harms of use & 326 (49\%) & $74(44 \%)$ & $114(47 \%)$ & $138(55 \%) \dagger$ & $149(46 \%)$ & $177(53 \%)$ \\
\hline Nicotine content & $85(13 \%)^{\star}$ & $26(15 \%)$ & 32 (13\%) & $27(11 \%)$ & 42 (13\%) & $43(13 \%)$ \\
\hline Purchase price of product & $77(12 \%)$ & $14(8 \%)$ & $30(12 \%)$ & $33(13 \%)$ & $42(13 \%)$ & $35(10 \%)$ \\
\hline General effects of use & $56(9 \%)$ & $26(15 \%) \dagger$ & $13(5 \%) \dagger$ & $17(7 \%)$ & $24(7 \%)$ & $32(10 \%)$ \\
\hline Tobacco cessation aid & $45(7 \%)$ & $11(6 \%)$ & $16(7 \%)$ & $18(7 \%)$ & $28(9 \%)$ & $17(5 \%)$ \\
\hline Flavour availability & $32(5 \%)$ & $10(6 \%)$ & $18(7 \%) \dagger$ & $4(2 \%) \dagger$ & $18(5 \%)$ & $14(4 \%)$ \\
\hline Monthly cost of use & $27(4 \%)$ & $7(4 \%)$ & $11(5 \%)$ & $9(4 \%)$ & $17(5 \%)$ & $10(3 \%)$ \\
\hline Device design & $10(2 \%)^{*}$ & $1(1 \%)$ & $6(2 \%)$ & $3(1 \%)$ & $6(2 \%)$ & $4(1 \%)$ \\
\hline Modifiability & $2(0 \%)^{*}$ & $0(0 \%)$ & $2(1 \%)$ & $0(0 \%)$ & $0(0 \%)$ & $2(1 \%)$ \\
\hline
\end{tabular}

${ }^{*} \mathrm{P}<0.05$ versus next higher ranked attribute for total sample.

$\dagger \mathrm{P}<0.05$ versus total sample for age groups. 
ENDS product was less harmful than tobacco cigarettes was extremely important to participants' choice. The level that the product was 'less harmful on my body as compared with tobacco cigarettes' had the highest partworth utility of any attribute (88.96). Moreover, the level that the product 'had the same amount of harm on my body as compared with tobacco cigarettes' caused people to avoid choosing that product and had a negative utility $(-22.45)$. Both the health effects and the use as a cessation aid had levels that are likely healthier and of more help in cessation than the evidence suggests. Yet in general, perceptions, including misperceptions, affect smokers' behaviour. ${ }^{37}$ The look and feel of cigarette packaging appears to influence consumers' use and may affect their perceptions' of the healthiness and harm of the cigarettes within. ${ }^{38}$ A study of combustible tobacco labelling revealed that 'additive-free' or 'natural' labels on current cigarette brands were misperceived to be possibly less harmful than other brands of cigarettes and may reduce the efficacy of public health initiatives. ${ }^{39}$ Even efforts by the Federal Trade Commission to prohibit language that might create misperceptions of reduced harm in tobacco cigarettes has been unsuccessful. ${ }^{37}$ This (mis) perception of harm and health appears to strongly influence the choice of ENDS products. Further efforts, including those studying clear labelling and health warnings, are needed to explore how to align ENDS users' perceptions of ENDS products with the evidence.

While harms of use had the highest importance score, the combined importance of purchase price and monthly cost was greater than harms of use, so the importance of financial burden on ENDS use should not be underestimated. If we combine the two cost-related attributes, purchase price and monthly cost, overall cost's importance score would be $24.1 \%$ as compared with $17.6 \%$ for health effects. A recent study of the cross-price elasticity of ENDS and tobacco cigarettes found that ENDS are partially substitutable for cigarettes. ${ }^{40}$ However, the availability of ENDS also reduced the number of individuals who reported they would quit smoking if cigarette costs increased by $20 \%$ (50.2\% to $30.0 \%$ ), revealing that ENDS may discourage smokers from quitting completely. ${ }^{41}$ Additionally, increase in the cost of ENDS products may shift consumers back towards combustible tobacco, though recent simulations found no relationship between cigarette prices and ENDS use. ${ }^{42}$ Taxation may reduce ENDS use but further work is needed to model the consequences of cost increase on ENDS use.

Potentially meaningful differences were found in the importance of ENDS product attributes and the most important attribute by different age groups. Younger and middle-aged adults found modifiability to be more important than older adults. While we did not see gender differences for attribute preferences, a Canadian DCE study of young women found that pack structure was the most important attribute driving ENDS use. ${ }^{14}$ The shape and structure of the device and packaging may be more important to a younger population. Younger adults were more likely to have general effects as their most important attribute while flavour availability was more likely to be most important to middle-aged adults and significantly less likely to be most important to older adults. A systematic review of studies of consumers' preference for flavour found it to be likely important to young people. ${ }^{7}$ However, as with our own qualitative study, which was included in the review, many of the included studies did not have experimental designs. ${ }^{16}$ Interestingly, another Canadian DCE study of ENDS use found that younger smokers perceived cherry flavour as less harmful while older adults found tobacco flavour less harmful. ${ }^{15}$ While we found flavour availability was more important to middle-aged adults, we did not find older adults favoured tobacco flavour. However, both of these studies found that attributes related to the users' health (harms of use in our case and health warnings in the Canadian study) were more important than flavour, and thus efforts to regulate flavours may not reduce ENDS use as much as other regulations on other attributes, such as harms of use.

Our study has several important limitations. First, our study examines choice behaviour and not actual purchase behaviour. While we drew from a national online survey panel, our respondent population is limited to a convenience sample. Additionally, best-worst scaling can be subject to attribute non-attendance where participants either fail to pay attention to an attribute or attributes, or attribute dominance where participants only pay attention to a single attribute. We found that only about $2 \%$ of participants did not attend to the majority of attributes, though about $16 \%$ failed to attend to at least one attribute. No participant showed dominance behaviour. While there was some attribute non-attendance, bestworst scaling inclines participants to make judgements about more attributes and does not invite as much attribute non-attendance or dominance as can be seen in other standard DCEs. However, it seems more likely that socially desirable responses could bias respondents' choices within best-worst scaling than other DCEs. ${ }^{24}$ Lastly, while we did extensive pretesting, it is possible that different participants interpreted different attributes and levels differently. For example, it is possible that participants viewed the monthly cost of use in relation to their own use and thus the responses to monthly cost may need to be viewed with caution.

\section{CONCLUSION}

A variety of ENDS product attributes are important to consumers. Harms of use had the highest importance to consumers' choice of an ENDS product. Other than cost, the attributes with the highest importance scores hinged on consumers' perceptions of efficacy as a harm reduction strategy (harms of use), general benefit (general effects) and tobacco cessation (cessation aid), respectively. Consumers differed by age group in some of the more important attributes. Though the overall importance of ENDS product attributes was similar, efforts to increase 
or decrease ENDS use could be tailored to these group differences.

\section{Author affiliations}

${ }^{1}$ Family Medicine, The University of North Carolina at Chapel Hill, Chapel Hill, North Carolina, USA

${ }^{2}$ Lineberger Comprehensive Cancer Center, University of North Carolina School of Medicine, Chapel Hill, North Carolina, USA

${ }^{3}$ Public Health Sciences, Wake Forest School of Medicine, Winston-Salem, North Carolina, USA

${ }^{4}$ Sawtooth Analytics, Sawtooth Software, Inc., Provo, Utah, USA

${ }^{5}$ Cecil G. Sheps Center for Health Services Research, The University of North Carolina at Chapel Hill, Chapel Hill, North Carolina, USA

${ }^{6}$ Epidemiology, University of North Carolina Gillings School of Global Public Health, Chapel Hill, North Carolina, USA

${ }^{7}$ Health Services Management and Policy, Ohio State University College of Public Health, Columbus, Ohio, USA

${ }^{8}$ RTI International, Research Triangle Park, North Carolina, USA

Acknowledgements We would also like to thank CHAl Core's Maihan Vu (MV) and Randall Teal (RT) for qualitative coding expertise. We would like to thank Trisha Crutchfield for her project management. The work reported in this paper was conducted by CHAI Core (Communication for Health Applications and Interventions), who is supported in part by a grant from NIH (DK056350) to the University of North Carolina Nutrition Obesity Research Center and from NCl (P30-CA16086) to the UNC Lineberger Comprehensive Cancer Center.

Contributors CEK, LMR, ELS, KC, MB, GAZ and AOG all contributed to the conceptualisation and design of the survey. CK and $K C$ assisted with data collection. CK, LMR, ELS, KC, CJW, CE, CM, MB, GAZ and AOG participated in the analysis of the data. All authors contributed to the content and reviewed the manuscript prior to submission.

Funding The University of North Carolina at Chapel Hill University Cancer Research Fund at the Lineberger Comprehensive Cancer Center supported this work. The attributes and factors in the experiment were developed with the assistance of the CHAl Core (Communication for Health Applications and Interventions), who is supported by the National Institutes of Health (DK056350) and the National Institutes for Health at the National Cancer Institute (P30 CA16086).

Competing interests None declared.

Patient consent for publication Not required.

Ethics approval The institutional review board at the University of North Carolina at Chapel Hill approved this study.

Provenance and peer review Not commissioned; externally peer reviewed.

Data sharing statement Data can be requested from Christine_Kistler@med.unc. edu.

Open access This is an open access article distributed in accordance with the Creative Commons Attribution Non Commercial (CC BY-NC 4.0) license, which permits others to distribute, remix, adapt, build upon this work non-commercially, and license their derivative works on different terms, provided the original work is properly cited, appropriate credit is given, any changes made indicated, and the use is non-commercial. See: http://creativecommons.org/licenses/by-nc/4.0/.

\section{REFERENCES}

1. Pauly J, Li Q, Barry MB. Tobacco-free electronic cigarettes and cigars deliver nicotine and generate concern. Tob Control 2007; $16: 357-57$

2. Jamal A, Phillips E, Gentzke AS, et al. Current cigarette smoking among adults - United States, 2016. MMWR Morb Mortal Wkly Rep 2018;67-53-9.

3. MacGuill S. What is the new tobacco data telling us: Euromonitor International. 2017. updated 20 Jun 2016. https://blog.euromonitor. com/2016/06/what-is-the-new-tobacco-data-telling-us.html (Accessed 21 Jan 2018).

4. Callahan-Lyon P. Electronic cigarettes: human health effects. Tob Control 2014;23 Suppl 2:ii36-ii40.

5. Backinger CL, Meissner HI, Ashley DL. The FDA "Deeming Rule" and tobacco regulatory research. Tob Regul Sci 2016;2-290-3.
6. Administration USFaD. FDA's Plan for Tobacco and Nicotine Regulation.

7. Zare S, Nemati M, Zheng Y. A systematic review of consumer preference for e-cigarette attributes: flavor, nicotine strength, and type. PLoS One 2018;13:e0194145.

8. de Bekker-Grob EW, Hol L, Donkers B, et al. Labeled versus unlabeled discrete choice experiments in health economics: an application to colorectal cancer screening. Value Health 2010;13:315-23.

9. Bech-Larsen T, Nielsen NA. A comparison of five elicitation techniques for elicitation of attributes of low involvement products. Journal of Economic Psychology 1999;20:315-41.

10. Marti J. Assessing preferences for improved smoking cessation medications: a discrete choice experiment. Eur $\mathrm{J}$ Health Econ 2012:13:533-48.

11. Marti J. A best-worst scaling survey of adolescents' level of concern for health and non-health consequences of smoking. Soc Sci Med 2012; 75:87-97.

12. Goto R, Takahashi Y, Ida T. Changes in smokers' attitudes toward intended cessation attempts in Japan. Value Health 2011;14:785-91.

13. Goto R, Nishimura S, Ida T. Discrete choice experiment of smoking cessation behaviour in Japan. Tob Control 2007;16:336-43.

14. Kotnowski K, Fong GT, Gallopel-Morvan K, et al. The impact of cigarette packaging design among young females in Canada: findings from a discrete choice experiment. Nicotine Tob Res 2016;18.

15. Czoli CD, Goniewicz M, Islam T, et al. Consumer preferences for electronic cigarettes: results from a discrete choice experiment. Tob Control 2016;25.

16. Kistler $\mathrm{C}$, Crutchfield T, Sutfin $\mathrm{E}$, et al. Consumers' preferences for electronic nicotine delivery system product features: a structured content analysis. International Journal of Environmental Research and Public Health 2017:14:613.

17. Hoek J, Thrul J, Ling P. Qualitative analysis of young adult ENDS users' expectations and experiences. BMJ Open 2017;7:e014990.

18. Keane $\mathrm{H}$, Weier M, Fraser D, et al. 'Anytime, anywhere': vaping as social practice. Critical Public Health 2017;27:465-76.

19. Kistler CE, Crutchfield TM, Sutfin EL, et al. Consumers' preferences for electronic nicotine delivery system product features: a structured content analysis. Int J Environ Res Public Health 2017;14.

20. Mühlbacher AC, Kaczynski A, Zweifel P, et al. Experimental measurement of preferences in health and healthcare using bestworst scaling: an overview. Health Econ Rev 2016;6:2.

21. Gendall P, Eckert C, Hoek J, et al. Estimating the effects of novel on-pack warnings on young adult smokers and susceptible nonsmokers. Tob Control 2018;27:519-25.

22. Hoek J, Gendall P, Eckert C, et al. Dissuasive cigarette sticks: the next step in standardised ('plain') packaging? Tob Control 2016;25:699-705.

23. Hoek J, Gendall P, Eckert C, et al. Effects of brand variants on smokers' choice behaviours and risk perceptions. Tob Control 2016:25:160-5.

24. Orme B. The maxdiff system technical paper. Technical Paper Series 2013 https://www.sawtoothsoftware.com/download/techpap/ maxdifftech.pdf (Accessed 8 Feb 2018).

25. Louviere JJ, Flynn TN. Using best-worst scaling choice experiments to measure public perceptions and preferences for healthcare reform in australia. Patient 2010;3:275-83.

26. Orme B. Accuracy of HB Estimation in MaxDiff Experiments. Sawtooth Software: Research Paper Series. Sequim, WA: Sawtooth Software, Inc, 2005.

27. West $R$, Raw M, McNeill A, et al. Health-care interventions to promote and assist tobacco cessation: a review of efficacy, effectiveness and affordability for use in national guideline development. Addiction 2015;110:1388-403.

28. Goniewicz ML, Gupta R, Lee YH, et al. Nicotine levels in electronic cigarette refill solutions: a comparative analysis of products from the U.S., Korea, and Poland. Int J Drug Policy 2015;26:583-8.

29. Cunny KA, Perri M. Single-item vs multiple-item measures of healthrelated quality of life. Psychol Rep 1991;69:127-30.

30. Heatherton TF, Kozlowski LT, Frecker RC, et al. Measuring the heaviness of smoking: using self-reported time to the first cigarette of the day and number of cigarettes smoked per day. $\mathrm{Br} J$ Addict 1989;84:791-9

31. Prevention CfDCa. National Adult Tobacco Survey Questionnaire, 2012-2013, 2014.

32. Szeinbach SL, Barnes JH, McGhan WF, et al. Using conjoint analysis to evaluate health state preferences. Drug Inf J 1999;33:849.

33. Flynn TN, Louviere JJ, Peters TJ, et al. Best-worst scaling: what it can do for health care research and how to do it. $J$ Health Econ 2007:26:171-89. 
34. Zhu SH, Sun JY, Bonnevie E, et al. Four hundred and sixty brands of e-cigarettes and counting: implications for product regulation. Tob Control 2014;23 Suppl 3:iii3-iii9.

35. National Academies of Sciences E, and Medicine. Public Health Consequences of E-Cigarettes. Washington, DC: The National Academies Press, 2018.

36. Carnevale R, Sciarretta S, Violi F, et al. Acute impact of tobacco vs electronic cigarette smoking on oxidative stress and vascular function. Chest 2016;150:606-12.

37. Yong $\mathrm{H}-\mathrm{H}$, Borland $\mathrm{R}$, Cummings $\mathrm{KM}$, et al. US smokers' beliefs, experiences and perceptions of different cigarette variants before and after the FSPTCA ban on misleading descriptors such as "light," "mild," or "low". Nicotine \& Tobacco Research 2016;18:2115-23
38. McNeill A, Gravely S, Hitchman SC, et al. Tobacco packaging design for reducing tobacco use. 2017.

39. Leas EC, Ayers JW, Strong DR, et al. Which cigarettes do Americans think are safer? A population-based analysis with wave 1 of the PATH study. Tob Control 2017;26:e59-e60.

40. Quisenberry AJ, Koffarnus MN, Hatz LE, et al. The experimental tobacco marketplace i: substitutability as a function of the price of conventional cigarettes. Nicotine Tob Res 2016;18.

41. Grace RC, Kivell BM, Laugesen M. Estimating cross-price elasticity of e-cigarettes using a simulated demand procedure. Nicotine Tob Res 2015;17:592-8.

42. Huang J, Tauras J, Chaloupka FJ. The impact of price and tobacco control policies on the demand for electronic nicotine delivery systems. Tob Control 2014;23 Suppl 3:iii41-iii47. 